Como citar: Witczak, M. V. C., Perez, K. V., Rodrigues, M. F. (2022). Impactos da pandemia COVID-19 nas vivências profissionais de residentes multiprofissionais em saúde. PSI UNISC, 6(1), 141-154. doi:

$10.17058 /$ psiunisc.v6i1.16658

\title{
Impactos da pandemia COVID-19 nas vivências profissionais de residentes multiprofissionais em saúde
}

\author{
Impactos de la pandemia COVID-19 en las vivencias profesionales de residentes \\ multiprofesionales en salud
}

\author{
Impacts of the COVID-19 pandemic in the experiences of multiprofessional health \\ residents
}

\author{
Marcus Vinicius Castro Witczak \\ Universidade de Santa Cruz do Sul (UNISC), Santa Cruz do Sul - RS/Brasil \\ ORCID: 0000-0002-4161-5920 \\ E-mail: marcus@unisc.br
}

Karine Vanessa Perez

Universidade de Santa Cruz do Sul (UNISC), Santa Cruz do Sul - RS/Brasil ORCID: 0000-0003-1643-8042

E-mail: karinevanessaperez@gmail.com

Makely Ferreira Rodrigues

Universidade de Santa Cruz do Sul (UNISC), Santa Cruz do Sul - RS/Brasil ORCID: 0000-0002-8876-8238

E-mail: makelyferreira@unisc.br

\begin{abstract}
Resumo
A pandemia COVID19 impôs aos serviços e trabalhadores da Saúde uma realidade inesperada. Desinformação sobre o vírus causador e o desenvolvimento da doença, o risco da exposição direta e o medo daí consequente, trouxeram aos profissionais novos desafios em suas jornadas e novas fontes de sofrimento e adoecimento mental. Inserem-se neste contexto os Programas de Residência Multiprofissional em Saúde e os residentes. Assim, este estudo, objetivou identificar os impactos da pandemia na saúde mental dos residentes multiprofissionais em saúde. Para o seu desenvolvimento, realizou-se uma pesquisa com os Residentes Multiprofissionais de um hospital de ensino do interior do Rio Grande do Sul, coletando-se dados (maio e junho de 2020) em um questionário semiestruturado. Obteve-se a participação consentida de 20 residentes. Os resultados evidenciam níveis elevados de estresse impactando no autocuidado. Diante disto, momentos de escuta psicológica (para relatarem seus medos, inseguranças e emoções) e o apoio psicossocial no ambiente de trabalho foram estratégias sinalizadas pelos residentes como importantes para enfrentamento do contexto pandêmico.
\end{abstract}

Palavras-chaves: Trabalho; Saúde mental; Coronavírus.

\section{Resumen}

La pandemia de COVID19 impuso una realidad inesperada a los servicios y trabajadores de la salud. La desinformación sobre el virus causante y el desarrollo de la enfermedad, el riesgo de exposición directa y el consiguiente miedo, supusieron nuevos retos para los profesionales en sus desplazamientos y nuevas fuentes de sufrimiento y enfermedad mental. Los Programas de Residencia Multiprofesional en Salud y los residentes se insertan en este contexto. Por ello, este estudio pretendía identificar los impactos de la pandemia en la salud mental de los residentes sanitarios multiprofesionales. Para su desarrollo, se realizó una encuesta con los Residentes Multiprofesionales de un hospital universitario del interior de Rio Grande do Sul, recogiendo datos (mayo y junio de 2020) en un cuestionario semiestructurado. Se obtuvo el consentimiento de participación de 20 residentes. Los resultados evidencian unos elevados niveles de estrés que impactan en el autocuidado. Ante esto, los momentos de escucha psicológica (para informar de sus miedos, inseguridades y emociones) y el apoyo psicosocial en el 
trabajo fueron estrategias identificadas por los residentes como importantes para afrontar el contexto de la pandemia.

Palabras clave: Trabajo; Salud mental; Coronavirus.

\begin{abstract}
The COVID19 pandemic imposed an unexpected reality on health services and workers. Misinformation about the causative virus and the development of the disease, the risk of direct exposure, and the resulting fear have brought new challenges to the professionals in their working lives and new sources of suffering and mental illness. The Multiprofessional Residency Programs in Health and the residents are inserted in this context.
\end{abstract}

Thus, this study aimed to identify the impacts of the pandemic on the mental health of multiprofessional health residents. For its development, a survey was conducted with the Multiprofessional Residents of a teaching hospital in the interior of Rio Grande do Sul, collecting data (May and June 2020) in a semi-structured questionnaire. The consent of 20 residents was obtained. The results show high levels of stress impacting selfcare. In view of this, moments of psychological listening (to report their fears, insecurities, and emotions) and psychosocial support in the workplace were strategies signaled by residents as important for coping with the pandemic context.

Keywords: Work; Mental health; Corona virus.

\section{Introdução}

A Organização Mundial da Saúde (OMS) declarou, em 30 de janeiro de 2020, que o surto da doença causada pelo novo coronavírus (SARS-CoV-2 - Severe Acute Respiratory Syndrome CoronaVirus - COVID19) constitui uma Emergência de Saúde Pública de Importância Internacional - o mais alto nível de alerta da Organização, conforme previsto no Regulamento Sanitário Internacional. Em 11 de março de 2020, a COVID-19 foi caracterizada pela OMS como uma pandemia. Até o dia de 26 de maio de 2021, o mundo já havia atingido a marca de mais de três milhões de mortos. Somente no Brasil, este número supera os 450 mil mortos, de acordo com o CoronaVirus Research Center da Johns Hopkins Universite of Medicine ${ }^{l}$.

Dada a sua amplitude e velocidade de propagação esta pandemia modificou substancialmente, em nível global, as relações sociais, especialmente às vivências cotidianas dos trabalhadores. Entendemos o trabalho e o trabalhar como fonte de subsistência e satisfação de necessidades identitárias e sociais e constituinte de nossa subjetividade e fundamental para o equilíbrio psíquico dos indivíduos. Assim, no contexto atravessado, tem-se diferentes e específicas situações: muitos passaram a realizar as suas atividades laborais em seus lares, afastados do ambiente organizacional cotidiano (home office); milhões ficaram desempregados, dado fechamento de empresas e impossibilidade de prestação de serviços; outros ainda, dada a natureza "essencial" de suas atividades, continuaram trabalhando e convivem com o medo do contágio, do adoecimento e da morte (para si ou seus familiares) (Witczak \& Kipper, 2020). Dentre estes últimos, destacamos os profissionais de saúde em ambiente hospitalar. E, de forma específica, os desafios enfrentados nos Programas de Residência Multiprofissional em Saúde (RMS).

A RMS caracteriza-se pelo ensino e formação em serviço e objetiva promover a especialização de graduados em diferentes áreas da saúde, capacitando o residente ao exercício profissional com excelência nas áreas de cuidado integral à saúde, da gestão e organização do trabalho e da educação em saúde (Silva, Contim, Ohl, Chavaglia, \& Amaral, 2015). Por essas características, há que se pensar a RMS como um espaço propício para a construção da identidade profissional. As trajetórias de formação possibilitam o alicerce para a construção de um contínuo aprendizado, e é nesse movimento de buscas, descobertas e transformações que vai se definindo tal identidade, à medida que vai percorrendo caminhos e construindo sua carreira ao longo da vida (Mazer \& Melo-Silva, 2010).

Este artigo apresenta o cotidiano de trabalho de Residentes Multiprofissionais em

\footnotetext{
${ }^{1}$ https://coronavirus.jhu.edu/map.html
} 
Saúde, de um hospital de ensino do interior de Rio Grande do Sul, durante a pandemia do novo coronavírus no ano de 2020. Os autores atuam e contribuem neste Programa de Residência, encontrando-se aí a motivação para tal escrito e dos objetivos deste estudo, que visam identificar os impactos da pandemia do novo coronavírus na saúde mental dos Residentes Multiprofissionais.

\section{Método}

Optou-se por uma metodologia exploratória, visto que esta oportuniza uma familiaridade com o problema, permitindo aprimorar ideias e intuições e considerando a relatividade de um caso em estudo (Gil, 2002). O campo de pesquisa trata-se um hospital de ensino do interior do Rio Grande do Sul, instituição que oferece atendimento a pacientes particulares, de convênios médicos e do Sistema Único de Saúde e neste momento conta com uma unidade estruturada para tratamento de pacientes com COVID-19. Os atores principais deste estudo são Residentes do Programa de Residência Multiprofissional em Saúde - com ênfase em Intensivismo, Urgência $e$ Emergência. A RMS possui dois anos de formação - identificados como Residentes do $1^{\circ}$ ano (R1) e Residentes do $2^{\circ}$ ano (R2) - e compõem o Programa as seguintes áreas: Educação Física, Enfermagem, Farmácia, Fisioterapia, Nutrição, Odontologia, Psicologia e Serviço Social. Para o seu desenvolvimento, utilizou-se um questionário semiestruturado com respostas em escala Likert e questões abertas disponibilizados na plataforma digital Googleforms nos meses de maio e junho de 2020. Este contou com 7 questões em escala Likert que buscavam identificar os impactos da pandemia na saúde mental, social e rotinas de autocuidado.

Para a participação, contatou-se todos os 40 Residentes multiprofissionais do Hospital de ensino, através do e-mail institucional, convidando-os para participar voluntariamente da pesquisa. Destes, 20 Residentes Multiprofissionais aceitaram o convite e responderam o questionário semiestruturado de forma voluntária e anônima. Os participantes são identificados pela letra $\mathrm{R}$ seguida de um número atribuído à ordem de acesso à plataforma descrita, por exemplo: R1 será a sigla usada para designar o primeiro residente a responder ao questionário e assim por diante, até o vigésimo respondente (R20). O perfil dos respondentes é demonstrado nas Figuras 1 e 2.

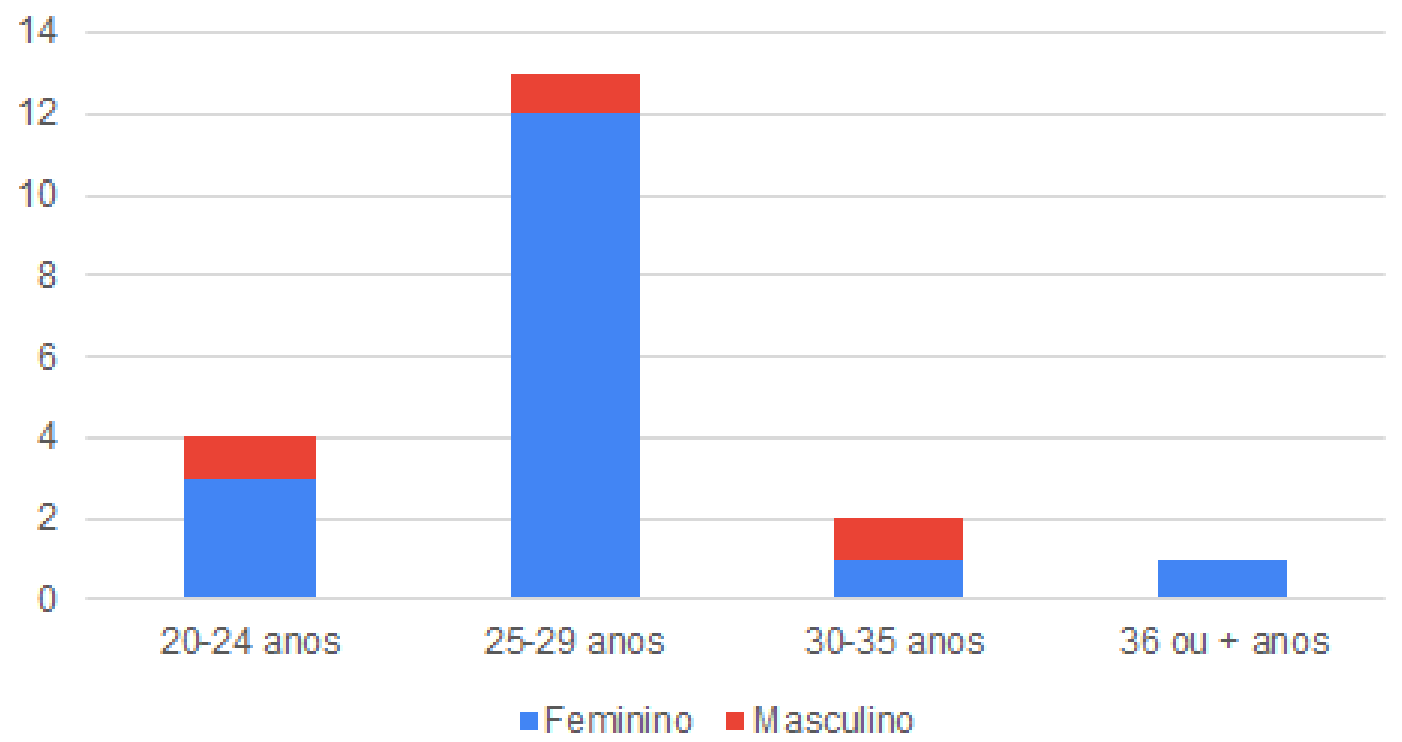

Figura 1. Perfil dos Residentes Multiprofissionais em Saúde: gênero e faixa etária Fonte: dos autores. 


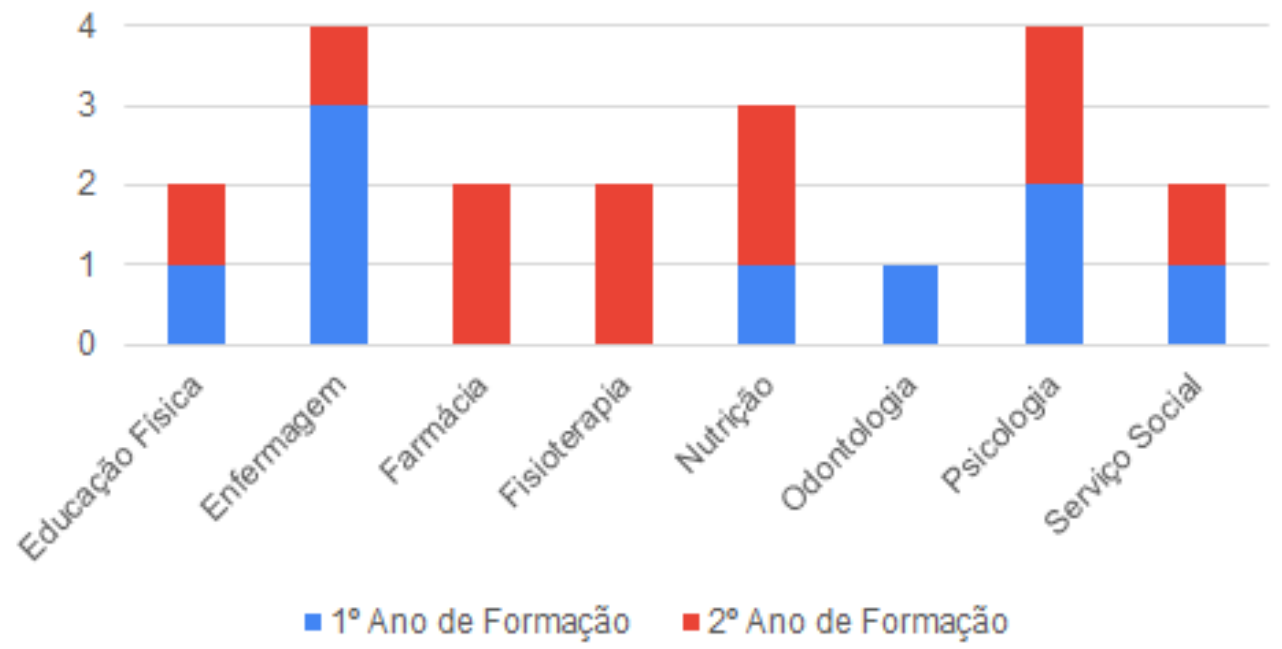

Figura 2. Perfil dos Residentes Multiprofissionais em Saúde por área do conhecimento e ano de formação

Fonte: dos autores.

Para a análise das questões abertas, utilizou-se a técnica de Análise de Conteúdo (Bardin, 1977), que propõe que o material, após transcrito, seja submetido à uma primeira leitura exploratória, seguido das fases de organização, sistematização e categorização. Produziram-se duas categorias temáticas, vivências de confrontamento e estratégias de enfrentamento. Estas serão apresentadas a seguir no item resultados e discussão.

Ressalta-se que o processo de pesquisa foi submetido e aprovado no Comitê de Ética em Pesquisa respectivo $\left(\mathrm{n}^{\circ}\right.$ CAAE 7481019.8.0000.5343 $\mathrm{n}^{\circ}$ do parecer do CEP 3.894.949.) e que todos os respondentes concordaram com a utilização das informações prestadas através de assinatura digital do Termo de Consentimento Livre e Esclarecido

\section{Resultados e discussão}

Para a apresentação dos resultados encontrados e com o intuito de fundamentar esta discussão, consideramos dois conceitos centrais como condutores desta discussão: trabalho e saúde (especialmente, saúde mental). $\mathrm{E}$, de forma transversal, todas as implicações que o momento pandêmico trouxe. Isto pois, segundo Witczak e Kipper (2021), em um mundo globalizado, com novas dimensões de tempo e espaço produzidas, o vírus SARSCoV chega até nós brasileiros muito antes do primeiro caso de doença ser oficialmente registrado. Isto porque já convivíamos "com ele nos noticiários, nas redes sociais, na desinformação das fake news. Produzia-se, no senso comum, um imaginário que remetia a situações apocalípticas, como o das produções cinematográficas" (p. 19).

Se a globalização e a evolução de novas tecnologias já vinham impondo adaptações a outros modos de trabalhar, em novos formatos de relações profissionais e em velocidade vertiginosa, a pandemia COVID-19 parece ter acelerado este processo ainda mais. Para Kipper et al. (2021, p. 61), este momento histórico "nos fez ressignificar grandes certezas e o lockdown das portas nos fez abrir para os outros através da necessidade da empatia e cooperação". Faz-se necessário então repensarse como o binômio conceitual trabalho/saúde, e os processos subjetivos e organizacionais daí subjacentes, estão sendo compostos.

O trabalho é uma prática humanizadora - ordenando atividades e ações e criando diferentes e novas formas de agir (Spink, 1996) e transformadora - pois garante ao mesmo tempo, a sobrevivência e a realização humana (Zanelli, 2014). Tal ideia é corroborada por Codo, Soratto e Vasques-Menezes (2014) ao afirmarem que esta é a "capacidade de construir-se a si próprio e a espécie, produzindo e reproduzindo a si próprio e a espécie' (p. 
279), e o fazer do trabalho é fundamental neste processo.

Adotamos aqui o conceito ampliado de saúde, "apreendido enquanto um fenômeno integral, integrador e potencializador de um viver com mais saúde" (Dalmolin et al, 2011, p. 390). Ou seja, a saúde decorre de um processo dinâmico, dialético e multifacetado que se denominou biopsicossocial. Pois, é no entrelaçamento das dimensões biológicas, psicológicas e sociais que se constituem os processos de manter-se saudável ou de se adoecer. Ignorar tais implicações é desvincular os sujeitos de seus processos sociais de vida, é um olhar para a doença, para o patológico e para o individual (Puttini, Pereira Junior, \& Oliveira, 2010; Limongi-França, 2012) e das implicações éticas e relacionais próprias da condição humana (Limongi-França, 2008). Já, a saúde mental, em definição da OMS (2008), produz-se na sensação de bem-estar, no desenvolvimento de habilidades, no enfrentamento de estressores e em uma vida produtiva e comunitária.

Paparelli, Sato e Oliveira (2011) ao discutirem sobre as inúmeras produções científicas no Brasil e no mundo que correlacionam os conceitos de saúde mental e trabalho, se indagam: "porque ainda precisamos falar sobre o tema?" (p. 119). E respondem, porque normalmente se remete aos indivíduos a responsabilização pelo seu próprio adoecer, culpabilizando-o. E, porque ainda há uma crença generalizada na "adoção da naturalização da ideia de que o trabalho produz sofrimento e não pode ser mudado, como se isso fosse um destino, uma determinação inquestionável e intransponível, cujo curso seria impossível de ser modificado" (p. 119).
Os autores remetem ao desgaste mental (conceito de Edith Seligmann-Silva, 1994; 2011) como figura daquilo que atrita é atritado, daquilo que se desgasta ao mesmo tempo que é desgastado.

Diferentes autores (Burhamah et al., 2020; Cherepanov et al., 2020; Ivbijaro, Brooks, Kolkiewicz, Sunkel, \& Long, 2020; Gnanavel et al., 2020; Kishor et al., 2020; Mohindra, R., Suri, Bhalla, \& Singh, 2020; Moorthy \& Sankar, 2020) têm apontado para os fatores que atribuem as relações entre prazer e sofrimento e que podem gerar o adoecimento dos trabalhadores em saúde durante esta pandemia do COVID-19. A partir dos dados coletados e sistematizados dos depoimentos dos Residentes Multiprofissionais em Saúde, construíram-se duas categorias temáticas, vivências de confrontamento e estratégias de enfrentamento. Sua apresentação e discussão serão apresentadas a seguir.

\section{Vivências de confrontamento}

Esta categoria apresenta e discute aspectos relacionados ao impacto psíquico resultante do confrontamento dos Residentes Multiprofissionais em Saúde com os processos de trabalho no período da pandemia COVID19. Ressalta-se que a maioria dos participantes (16) afirmaram manterem-se nas atividades rotineiras à sua formação, ou seja, àquelas prescritas pelo Programa de Residência Multiprofissional. No entanto, quatro deles tiveram suas rotinas modificadas por estarem atuando diretamente no contexto da pandemia, em um local nomeado como "Unidade COVID19". A Figura 3 permite a visualização desta correlação: 


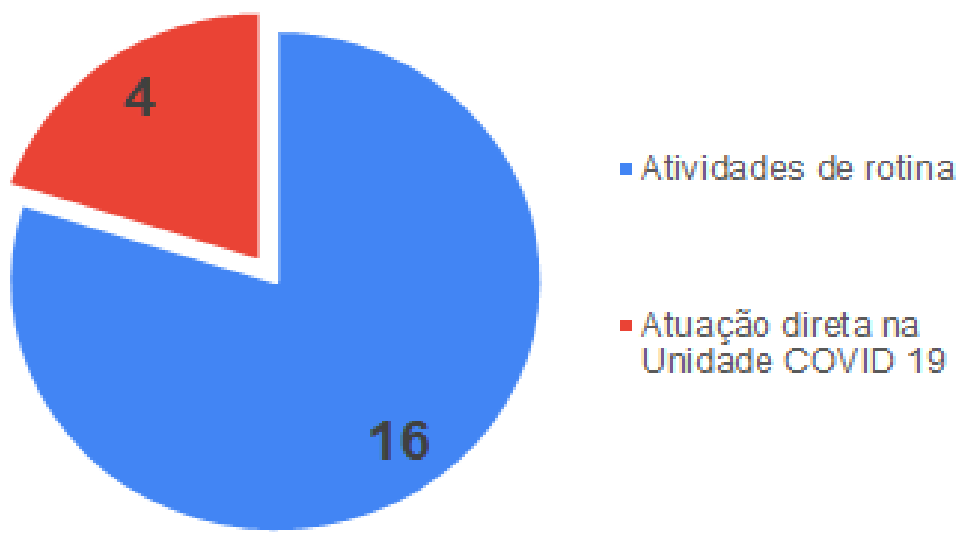

Figura 3. Mudança de rotinas dos Residentes Multiprofissionais em Saúde entrevistados Fonte: dos autores.

Segundo Cruz et al. (2020) internacionalmente, os estudos recentes acerca dos impactos na saúde mental dos profissionais de saúde, que lidam diretamente com populações infectadas pelo COVID-19, discutem a relação entre o temor pela exposição ao contágio, a situação de isolamento e confinamento e as medidas de quarentena implementadas. Entre os profissionais expostos diretamente aos riscos de contaminação, especialmente aqueles que atuam em hospitais e postos de saúde, há registros de exaustão, redução da empatia, ansiedade, irritabilidade, insônia e decaimento de funções cognitivas e do desempenho. A Figura 4 demonstra as principais percepções apontadas pelos RMS nas mudanças do seu cotidiano de trabalho:

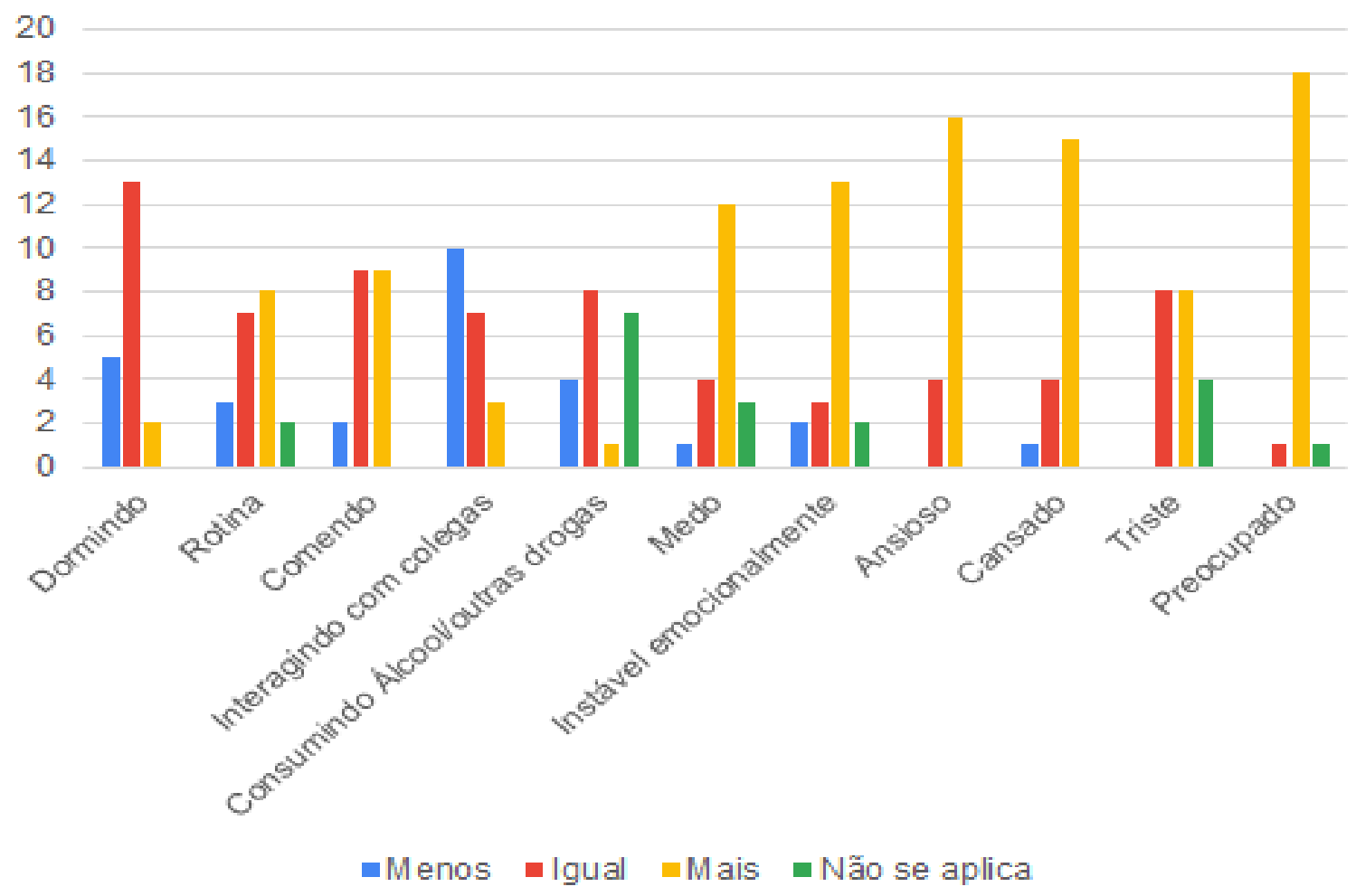

Figura 4. Sintomas associados às mudanças de rotinas dos Residentes Multiprofissionais em Saúde Fonte: dos autores. 
Os depoimentos a seguir corroboram as informações da Figura 4:

Como estou muito ansiosa, estou tendo dor no peito, labirintite $e$ bruxismo. Isso está atrapalhando meu desempenho profissional. (R5)

Logo no início da pandemia, eu estava mais ansiosa, com medo, angustiada e insegura, mas atualmente, tenho conseguido me adaptar e lidar melhor com esse momento. Com a pandemia, em alguns momentos, estou muito ansiosa, apresentando sintomas como dor de cabeça e no estômago $e$ taquicardia. (R12)

Os dados coletados demonstram que a atividade assistencial expõe os Residentes Multiprofissionais ao temor do contágio, gerando reações emocionais diversas diante de tal preocupação. Em análise às respostas ao questionário semiestruturado, identifica-se que, apesar da maior parte dos profissionais não terem atuado diretamente com risco de contaminação, evidenciam manifestações em níveis elevados de estresse e do autocuidado. Veja-se:

Muito ansiosa, tensa, preocupada, muita incerteza, sensação de eu ser um "meio de transmissibilidade" do coronavírus devido trabalhar no Hospital. (R14)

Exausta mentalmente, sem vontade de mudar o cenário por falta de interesse. (R4);

Vasconcellos-Silva e Castiel (2020, p. 2) apontam que há, em nível de informações uma "vacuidade de certezas, proliferam versões distorcidas de conceitos e fatos científicos" e apontam o papel da mídia, das redes sociais e das fake news na disseminação massiva disto, e consequentemente, da produção de um imaginário social. Reações semelhantes são apontadas por Residentes Multiprofissionais que não se encontram na unidade de risco (setor COVID):
Tenho sentido cansaço e desgaste físico e emocional bem grande, inclusive, porque apesar de não atuarmos diretamente no setor COVID não estamos livres de contrair $o$ vírus e transmitir aos outros. Como tenho filhos pequenos me preocupo muito com esta questão e do risco que posso estar colocando eles. (R16)

Para Lancman e Ghirardi (2002) o ato de trabalhar permite o confronto entre o mundo externo e mundo interno do trabalhador. A externalidade, ou o mundo pandêmico, confronta-se com tudo aquilo que o constitui (lógicas e ditames sociais). Tal confrontamento, entre os novos procedimentos de segurança epidemiológica (condições) e as "novas" relações de trabalho (organização), podem gerar às equipes e aos Residentes Multiprofissionais, mais especificamente, sofrimento psíquico:

\section{Apesar de alguns plantões não serem tão cansativos, eu saio sempre cansada da mesma forma. $O$ uso de máscara em um plantão de $12 \mathrm{~h}$ também incomoda bastante. (R15)}

Em minha área as atividades foram bastante afetadas, tendo que acontecer readequações que acredito que comprometam em parte a qualidade do aprendizado da residência. (R3)

Por outro lado, o bem-estar e o prazer correspondem a uma diminuição da carga psíquica do trabalho, questão que se torna um instrumento de equilíbrio para o trabalhador (Flores \& Moura, 2018). Contudo, observa-se instabilidade emocional nos Residentes Multiprofissionais, tornando o trabalho ameaçador à saúde mental, por se opor a liberdade e a criatividade (Silva, Santos, \& Oliveira, 2020). Vejamos a fala:

[...] com a passagem do tempo e me informando sobre os devidos cuidados, sinto que consigo realizar 
meu trabalho sem ter a preocupação específica com o COVID-19. (R8)

Apreensiva, ao mesmo tempo estou feliz e realizada de me desenvolver profissionalmente sinto medo em ser fonte de transmissão do vírus para as pessoas que amo. (R18)

Ampliando-se este quadro, Merhy e Franco (2008, p. 430) ressaltam que "todo trabalho é mediado por tecnologias e depende da forma como elas se comportam no processo de trabalho; pode-se ter processos mais criativos, centrados nas relações, ou processos mais presos à lógica dos instrumentos". E, para Amazarray, Câmara e Carlotto (2014) tal complexidade não envolve apenas a execução técnica (regras e procedimentos), mas também uma diversidade de habilidades e competências demandadas das situações vividas. Possibilitando o reconhecer-se a si mesmo perante as escolhas profissionais, potencializando-se no reconhecimento social do seu fazer e gratificando-o com um sentimento de pertencimento. Ainda que o momento seja como de temor frente a possibilidade de contágio e transmissão do vírus SARS-COV-2, estes afirmam que são reconhecidos e valorizados:

A Fisioterapia tem sido peça chave no tratamento dos pacientes com COVID-19, o que nos gera o sentimento de extrema gratidão $e$ também valorização profissional. (R7)

Em complementaridade, $\mathrm{o}$ ato de trabalhar envolve uma discrepância entre o que foi prescrito e a situação real/concreta de atuação, de tal modo que os trabalhadores se mobilizam física, cognitiva e emocionalmente para preencher essa lacuna. Em um estudo com enfermeiros de um hospital geral, Falavigna e Carlotto (2013) apontam correlações diretas entre as demandas (ou cargas) do trabalho, o sofrimento e $\mathrm{o}$ adoecimento mentais e o absenteísmo. Associando-se a sobrecarga "a necessidade constante de estudo para aperfeiçoamento, treinamento de equipe e reuniões administrativas que excedem à carga horária" (p. 368), situação muito semelhante a vivida pelos Residentes Multiprofissionais.

Acredito que o residente em si poderia ter mais voz, visto que nossas ideias e sugestões na maioria das vezes não são aceitas (...) acredito que todo preceptor e tutor deveria um dia ter a experiência de ter sido residente. (R19)

Na perspectiva do trabalho vivo em ato (Merhy, 2008) tem-se o alerta de que o caminho a ser percorrido entre o trabalho prescrito e o real, deve ser a cada momento, inventado e reinventado pelo sujeito. Assim, os profissionais de saúde precisam compreender seu desempenho profissional como resultantes das suas atividades desempenhadas.

Estou atuando na Unidade COVID que está muito bem estruturada e organizada, o que tem facilitado bastante o meu trabalho. (R6)

Diante do exposto, evidencia-se que o trabalho é tudo aquilo que implica o ato de trabalhar: gestos, saber-fazer, engajamento do corpo, mobilização da inteligência e da criatividade, capacidade de refletir, de interpretar, de sentir e de reagir às situações. É necessário compreendê-lo como dimensão de constituição da identidade e meio de inserção social, o que significa considerar a atividade ocupacional para além da questão de sobrevivência econômica (Amazarray, Câmara, \& Carlotto, 2014). Para Coutinho, Krawulski e Soares (2007, p. 37) a identidade na contemporaneidade, requer "dos sujeitos que se identifiquem, a cada momento, com algo novo, e reconheçam em suas trajetórias uma dimensão temporal, integrando passado, presente e futuro, no mundo laboral. [...] as mudanças [...] trazem exigências de novas competências, habilidades e talentos [...] levam o sujeito a ter que enfrentar cotidianamente o novo e reescrever sua trajetória de vida". Assim: 
Acredito que se trata de um momento diferente e inesperado por todos. Isso inevitavelmente acaba causando alterações importantes nas expectativas geradas acerca da residência. [...]. (R17)

Os sentimentos muitas vezes adversos e os processos de trabalho novos e desgastantes trouxeram aos Residentes Multiprofissionais vivências de confrontamento como as demonstradas, dado o ambiente pandêmico. Porém, há nuances diferentes para os $\mathrm{R} 1$ e os R2: enquanto os primeiros ainda se aclimatavam ao ambiente hospitalar e a própria estrutura da RMS, os segundos tiveram rotinas e processos de ensino e trabalho radicalmente modificados. $\mathrm{Na}$ seção seguinte apresentaremos e discutiremos as estratégias de enfrentamento.

\section{Estratégias de enfrentamento}

Esta categoria discute e apresenta as correlações entre a transformação do sofrimento patogênico em sofrimento criativo na concepção dejouriana e as estratégias de enfrentamento dos Residentes da Residência Multiprofissional em Saúde como suportes emocionais diante deste contexto. Oliveira e Mendes (2014, p. 392), ao realizarem uma síntese do pensamento de Dejours, Abdoucheli e Jayet (1994), ressaltam que não se pode negar o sofrimento do sujeito nas organizações de trabalho, mas que a sua elaboração a partir de "estratégias criativas que, em geral, favorecem à saúde do sujeito e à produção". Enquanto àquele sofrimento designado como patogênico "ocorre quando o trabalhador esgota seus recursos defensivos, levando-o à descompensação e à doença".

Para Dejours (1996, p. 170), estas possibilidades criativas decorrem da "construção de um espaço de palavra, de inteligibilidade, transparência, visibilidade, exteriorização, confiança, solidariedade, reconhecimento, o que faz aparecer nas relações de trabalho uma dimensão diversa da técnica". Estes elementos positivos de enfrentamento puderam ser vistos:
[...] Procuro manter boas relações $e$ quando estou me sentindo triste ou preocupada tenho colegas com as quais consigo desabafar, ser ouvida. (R16).

Muitos destes problemas estão associados ao sentimento de medo em relação ao momento pandêmico, que Silva et al. (2020, p. 5) compreendem como "uma reação natural e sadia diante de uma ameaça real e eminente, que demanda muitas vezes um agir racional para seu enfrentamento, pautado em informações realistas e concretas, com a finalidade de subsidiar, nesse caso, as medidas de proteção disponíveis".

Logo no início da pandemia, eu estava mais ansiosa, com medo, angustiada e insegura, mas atualmente, tenho conseguido me adaptar e lidar melhor com esse momento. (R12).

Cruz et al. (2020, p. 10), em manifesto publicado na Revista de Psicologia Organizacional e do Trabalho, literalmente afirmam que "vivemos uma situação de crise e emergência, com reflexos sociais, econômicos e na saúde física e mental das populações. [...]. Entretanto, constata-se neste momento de enfrentamento à contaminação, a proliferação de problemas na saúde mental das pessoas". A pandemia além de proporcionar instabilidade emocional vem sendo marcada por mudanças significativas na rotina e organização de trabalho dos Residentes Multiprofissionais, logo, observa-se esse impacto como ameaça à saúde mental dos profissionais. $\mathrm{O}$ aumento de responsabilidade, controle do trabalho e do tempo, jornada de trabalho alterada, incertezas do momento, medo da contaminação, são fatores desencadeantes de cansaço e insatisfação (Silva et al., 2020; Cruz et al., 2020).

Ao mesmo tempo, as práticas e medidas de segurança no ambiente hospitalar destacam novos comportamentos e necessidades ao trabalhador em saúde, tais como: sentir dificuldades que não existiam antes, como realizar sozinho tarefas que antes eram 
compartilhadas; o uso de equipamentos (EPIs) e recursos novos e ou diferentes dos habituais; prolongamento da jornada ou aceleramento dos ritmos e outras formas de execução do trabalho antes não usuais; e, finalmente, novos procedimentos em atendimento direto aos pacientes, às famílias destes e a comunidade em geral (Almeida, 2020).

Realmente criar um fluxo de atendimentos e respeitá-lo. Não alterar este de um dia para a noite sem notificação ou informação aos demais profissionais. (R4)

Entender a influência da organização do trabalho na qualidade de vida, na saúde mental, no desgaste e no adoecimento dos trabalhadores é fundamental para a compreensão e para a intervenção em situações que podem levar a diversas formas de sofrimento. A exposição constante ao agente infeccioso cria apreensão de ser contaminado e espalhar o vírus para os entes queridos. Ansiedade crônica, culpa, desamparo, isolamento e insônia podem prejudicar o funcionamento. Ter refeições regulares, sono e intervalos adequados interjornadas, são vitais. Apoio construtivo de pares, terapia de apoio e intervenções precoces de saúde mental contribuem bastante para reduzir o absenteísmo e melhorar sua qualidade de atendimento, tanto para si quanto para os pacientes (Lancman \& Ghirardi, 2002; Banerjee, 2020). Em complementaridade, Cherepanov (2020) ao analisarem condições de trabalho e saúde mental de trabalhadores em saúde no Reino Unido enfatizam que os serviços precisam ser revistos nos seguintes itens: fomentar o apoio entre pares, ajustar padrões de cultura organizacional, melhorar processos de capacitação e supervisão e fortalecer lideranças para o enfrentamento das situações de crise.

Considero que seria importante momentos de pausa ao longo do dia de trabalho em que fosse possível realizar ginástica laboral, práticas de relaxamento, respiração ou quaisquer outras atividades com foco no cuidado da saúde mental. (R12)
O trabalhador da saúde é sempre coletivo. O "trabalho em saúde" é sempre realizado por um trabalhador coletivo. Não há trabalhador da saúde que dê conta sozinho do mundo das necessidades de saúde (Merhy \& Franco, 2009). É nas relações que ocorrem a partir do trabalho que se permite o desenvolvimento da identidade e a transformação do sofrimento em prazer, a partir do olhar do outro e da valorização decorrente desse olhar (Lancman \& Ghirardi, 2002). Os entrevistados ressaltam esta necessidade:

Sinto, de modo geral, falta de apoio. Pouco acesso a diálogo, o que nos deixa inseguros. Buscamos apoio uns nos outros e em nossas preceptorias/tutorias [...]. (R8)

Reunião de feedback entre residentes, COREMU e preceptores, para cada um falar como está sendo a experiência, o que está agradando, o que poderia melhorar, uma maneira de desabafarmos e ao mesmo tempo, de deixarmos a coordenação ciente de tudo que está acontecendo $e$ possibilitar a melhora do programa de residência. (R10)

Em atenção à saúde mental, Silva, Santos e Oliveira (2020) enfatizam que é preciso uma atenção especial às demandas psicológicas emergentes no cenário atual. Tal necessidade também é sinalizada pelos Residentes Multiprofissionais como alternativa de enfrentamento. Nas falas, salientam que os espaços de escuta e acolhimento, deveriam ser conduzidos por psicólogos:

Conversas em

grupos/acompanhamento $d a$ equipelacompanhamento psicológico. (R7)

Grupos de psicoterapia para os profissionais atuantes na linha de frente. (R9)

O Ministério de Saúde (Brasil, 2020) sugere em uma cartilha produzida durante a pandemia, que a saúde mental dos profissionais 
de saúde seja assistida de forma continuada e entendida como um dos pilares prioritários, uma vez que pode fortalecer a rede de resiliência no enfrentamento dessa pandemia. Especialmente, por entender que gerenciar a saúde mental dos profissionais e o bem-estar psicossocial destes durante esse período, é tão importante quanto gerenciar sua saúde física, principalmente para que eles possam ter melhor capacidade de cumprir seus papéis e desenvolver suas atividades. Em concordância com os autores e acolhendo as necessidades dos Residentes, após a pesquisa, inicia-se o projeto $(\mathrm{Re})$ construindo: escuta de práticas. Trata-se de um projeto institucional, que tem como objetivo, realizar encontros mensais com os Residentes, com a proposta de ofertar suporte organizacional através de escuta, acolhimento e problematização das demandas psíquicas relacionadas à organização do trabalho.

\section{Considerações finais}

Diante desta pandemia, alerta-se para a saúde mental dos profissionais de saúde, que passam a correr risco aumentado para desenvolvimento de doenças ocupacionais, já que possuem medo, insegurança e apreensão com o avanço da doença. Estes, ao se conectarem as práticas de trabalho, não temem apenas o próprio contágio, mas também a transmissão para suas famílias.

Assim, diante do que se discute mundialmente, bem como evidenciado pelos Residentes Multiprofissionais nesta pesquisa, o acompanhamento psicológico torna-se essencial para que esses profissionais possam continuar investindo no seu trabalho enfrentando os desafios postos por este novo contexto da jornada de trabalho. Portanto, recomenda-se que as instituições ofertem suporte psicossocial aos trabalhadores para que, numa situação de sobrecarga, sofrimento e estresse, como a vivenciada na experiência da pandemia, eles possam além de relatar seus medos, inseguranças e emoções, contar com apoio no âmbito da saúde mental no ambiente de trabalho.

\section{Referências}

Almeida, I. M. (2020). Proteção da saúde dos trabalhadores da saúde em tempos de COVID-19 e respostas à pandemia. Revista Brasileira de Saúde Ocupacional, 45, e17. Recuperado de https://www.scielo.br/pdf/rbso/v45/23176369-rbso-45-e17.pdf.

Amazarray, M. R., Câmara, S. G., \& Carlotto, M. S. (2014). Investigação em saúde mental e trabalho no âmbito da saúde pública no Brasil. In A. R. C. Merlo, C. Bottega, \& K. V. Perez. (Eds.), Atenção à saúde mental do trabalhador: sofrimento e transtornos psíquicos relacionados ao trabalho. (pp. 75-92). Porto Alegre: Evangraf.

Bardin, L. (1977). Análise de conteúdo. Lisboa: Edições 70.

Banerjee, D. (2020). The COVID-19 outbreak: crucial role the psychiatrists can play. Asian Journal of Psychiatry, 50, 102014.

Recuperado de https://www.sciencedirect.com/science/arti
cle/abs/pii/S1876201820301258?via\%3Dih ub.

Brasil. (2020). Recomendações de proteção aos trabalhadores dos serviços de saúde no atendimento de COVID-19 e outras sindromes gripais. Recuperado de https://www.saude.go.gov.br/files/banner_c oronavirus/GuiaMS-

RecomendacoesdeprotecaotrabalhadoresCOVID-19.pdf.

Burhamah, W., AlKhayyat, A., Oroszlányová, M., AlKenane, A., Almansouri, A., Behbehani, M., ... AlSuwaidan, M. (2020). The psychological burden of the COVID19 pandemic and associated lockdown measures: Experience from 4000 participants. Journal of Affective Disorders, 277, 977-985. doi 10.1016/j.jad.2020.09.014

Coutinho. M. C., Krawulski, E., \& Soares, D. H. P. (2007). Identidade e trabalho na contemporaneidade: repensando 
articulações possíveis. Psicologia \& Sociedade, 19(ed. esp), 29-37, Recuperado de

https://www.scielo.br/j/psoc/a/nN9wNGSfz dr9VxZkRSJqimk/?format=pdf\&lang=pt

Cherepanov E. (2020). Responding to the Psychological Needs of Health Workers During Pandemic: Ten Lessons From Humanitarian Work. Disaster medicine and public health preparedness, 1-7. doi: 10.1017/dmp.2020.356

Codo, W., Soratto, L., \& Vasques-Menezes, I. (2014). Saúde mental e trabalho. In J. C. Zanelli, (Org.), Psicologia, organizações e trabalho no Brasil (pp. 276-299). Porto Alegre: Artmed.

Cruz, R. M., Borges-Andrade, J. E., Moscon, D. C. B., Micheletto, M. R. D., Esteves, G. G. L., Delben, P. B., Carlotto, P. A. C. (2020). COVID-19: emergência e impactos na saúde e no trabalho. Revista Psicologia: Organizações e Trabalho, 20(2), I-III. Recuperado de http://pepsic.bvsalud.org/pdf/rpot/v20n2/v2 0n2a01.pdf.

Dalmolin, B. B., Backes, D. S., Zamberlan, C., Schaurich, D., Colomé, J. S., Gehlen, M. H. (2011) Significados do conceito de saúde na perspectiva de docentes da área da saúde. Esc. Anna Nery, 15(2), 389-394. doi: 10.1590/S1414-81452011000200023

Dejours, C. (1996). Uma nova visão do sofrimento humano nas organizações. In J. Chanlat \& O. L. S. Tôrres (Eds.), $O$ indivíduo na organização: dimensões esquecidas (pp. 149-173; $3^{\mathrm{a}}$ ed.). São Paulo: Atlas.

Dejours, C., Abdoucheli, E., \& Jayet. C. (1994). Psicodinâmica do trabalho: Contribuições da escola Dejouriana à análise da relação prazer, sofrimento e trabalho. São Paulo: Atlas.

Falavigna, A., \& Carlotto, M. S. (2013). Tendência Temporal de Afastamento do Trabalho por Transtornos Mentais e Comportamentais em Enfermeiros (19982008). Revista Psicologia: Organizações e Trabalho, 13(3), 363-372. Recuperado de http://pepsic.bvsalud.org/pdf/rpot/v13n3/v1 $\underline{3 \mathrm{n} 3 \mathrm{a} 12 . \mathrm{pdf}}$
Flores, V. D. C. \& Moura, E. P. G. (2018).

Significados do trabalho, prazer e

sofrimento no ofício de Agentes

Funerários. Revista Psicologia:

Organizações e Trabalho, 18(1), 326-334.

Recuperado de

http://pepsic.bvsalud.org/pdf/rpot/v18n1/v1 8n1a07.pdf

Gil, A. C. (2002). Como elaborar projetos de pesquisa. São Paulo: Atlas.

Gnanavel, S, Maiti T., Sharma, P., Kaur, D., Kaligis, F., Chang, J. P.-C., ... Grottaglie, A. D. (2020). Challenges and opportunities for early career child mental health professionals during the COVID19 pandemic. Asian Journal of Psychiatry, 54(10), 24-43. doi: 10.1016/j.ajp.2020.102443.

Ivbijaro, G., Brooks, C., Kolkiewicz, L., Sunkel, C., \& Long, A. (2020).

Psychological impact and psychosocial consequences of the COVID 19 pandemic Resilience, mental well-being, and the coronavirus pandemic. Indian journal of psychiatry, 62(Suppl 3), S395-S403. doi: $10.4103 /$ psychiatry. IndianJPsychiatry 1031 20

Kipper, L. M., Witczak, M. V. C., Agnes, J. A., Grolli, D., Cruz, J. da, \& Rodrigues, M. F. (2021) Saúde mental e trabalho em tempos de pandemia COVID-19: relatos de vida. In L. L. Lasta, J. C. da Silva, \& M. V. C. Witczak (Orgs.), Pandemia COVID-19: saúde mental e práticas sociais. (pp. 6177). Santa Cruz do Sul, RS: EDUNISC.

Kishor, M, Shah, H., Chandran, S., Mysore, A. V., Kumar, A., Menon, V., ... Singh, O P. (2020). Psychiatry postgraduate examinations for 2020 in the middle of COVID19 crisis: Suggestions from Indian teachers of psychiatry. Indian J Psychiatry, 62(4), 431-434. Recuperado de https://pesquisa.bvsalud.org/globalliterature-on-novel-coronavirus-2019ncov/resource/pt/covidwho-738320

Lancman, S. \& Ghirardi, M. I. G. (2002). Pensando novas práticas em terapia ocupacional, saúde e trabalho. Rev. Ter. Ocup. Univ., 13(2), 44-50. Recuperado de 
https://www.revistas.usp.br/rto/article/view/ 13895.

Limongi-França, A. C. (2008). Psicologia do trabalho: psicossomática, valores e práticas organizacionais. São Paulo: Editora Saraiva.

Limongi-França, A. C., \& Rodrigues, A. L. (2012). Stress e trabalho: uma abordagem psicossomática. São Paulo: Atlas.

Mazer, S. M., \& Melo-Silva, L. L. (2010). Identidade Profissional do Psicólogo: Uma Revisão da Produção Científica no Brasil. Psicologia Ciência E Profissão, 30(2), 276295. Recuperado de http://pepsic.bvsalud.org/pdf/pcp/v30n2/v3 0n2a05.pdf

Merhy, E. E., \& Franco, T. B. (2009). Trabalho em Saúde. Dicionário da educação profissional em saúde. Rio de Janeiro: EPSJV.

Merhy, E. E., \& Franco, T. B. (2008). Reestruturação produtiva em saúde. In I. B. Pereira \& J. C. F. Lima. Dicionário da educação profissional em saúde. Rio de Janeiro: EPSJV.

Mohindra, R., R, R., Suri, V., Bhalla, A., \& Singh, S. M. (2020). Issues relevant to mental health promotion in frontline health care providers managing quarantined/isolated COVID19 patients. Asian journal of psychiatry, 51(10), 20-84. doi: 10.1016/j.ajp.2020.102084

Moorthy, A., \& Sankar, T. K. D. (2020). Emerging public health challenge in UK: perception and belief on increased COVID19 death among BAME healthcare worker. Journal of Public Health, 42(3), 486-492. doi: https://doi.org/10.1093/pubmed/fdaa096

Oliveira, J. N. \& Mendes, A. M. (2014). Sofrimento psíquico e estratégias defensivas utilizadas por desempregados: contribuições da psicodinâmica do trabalho. Temas psicol., 22(2), 389399. Recuperado de http://pepsic.bvsalud.org/pdf/tp/v22n2/v22n 2a11.pdf.

Organização Mundial da Saúde [OMS]. (2008). Integração da saúde mental nos cuidados de saúde primários - uma perspectiva global. Lisboa, Portugal: Ministério da Saúde.

Paparelli, R., Sato, L., \& Oliveira, F. de. (2011). A saúde mental relacionada ao trabalho e os desafios aos profissionais da saúde. Rev. Bras. Saúde Ocup., 36(123), 118-127. doi: 10.1590/S030376572011000100011

Puttini, R. F.; Pereira Junior, A.; Oliveira, L. R. de. (2010) Modelos explicativos em Saúde Coletiva: abordagem biopsicossocial e auto-organização. Physis Revista de Saúde Coletiva, Rio de Janeiro, 20 [3]: 753767, 2010. Recuperado de https://scielosp.org/pdf/physis/2010.v20n3/ 753-767/pt

Seligmann-Silva, E. (1994). Desgaste mental no trabalho dominado. Rio de Janeiro: Cortez.

Seligmann-Silva, E. (2011) Trabalho e desgaste mental: o direito de ser dono de si mesmo (1. ed.). São Paulo: Cortez.

Silva, J. C., Contim, D., Ohl, R. I. B., Chavaglia, S. R. R., \& Amaral, E. M. S. (2015). Percepção dos residentes sobre sua atuação no programa de residência multiprofissional. Acta Paul Enferm., 28(2), 132-138. Recuperado de https://www.scielo.br/pdf/ape/v28n2/19820194-ape-28-02-0132.pdf.

Silva, H. G. N.; Santos, L. E. S., \& Oliveira, A. K. S. (2020). Efeitos da pandemia no novo Coronavírus na saúde mental de indivíduos e coletividades. J. nurs. health., 10,1-10. Recuperado de https://docs.bvsalud.org/biblioref/2020/06/1 097482/4-efeitos-da-pandemia-do-novocoronavirus-na-saude-mental-dei_fNxf8zd.pdf.

Spink, P. K. (1996) Organização como fenômeno psicossocial: notas para uma redefinição da psicologia do trabalho. Psicologia e Sociedade: 8(1): 174-192. Recuperado de https://pesquisaeaesp.fgv.br/sites/gvpesquisa.fgv.br/files/ar quivos/spink__a_organizacao_como_fenomeno_psicosso cial.pdf 
Vasconcellos-Silva, P. R. \& Castiel, L. D. (2020). COVID-19, as fakes news e o sono da razão comunicativa gerando monstros: a narrativa dos riscos e os riscos das narrativas. Cad. Saúde Pública, 36(7), 112. Recuperado de https://www.scielo.br/pdf/csp/v36n7/16784464-csp-36-07-e00101920.pdf.

Zanelli, J. C., Borges-Andrade, J. E., \& Bastos, A. V. B. (2014). Psicologia, organizações e trabalho no Brasil (2. ed.). Porto Alegre: Artmed.
Witczak, M. V. C., \& Kipper, L. M. (2021). Saúde mental e trabalho em tempos de pandemia COVID-19 - construção de cenários através da pesquisa do Estado da Arte. In L. L. Lasta, J. C. da Silva, \& M. V. C. Witczak (Orgs.), Pandemia COVID-19: saúde mental e práticas sociais. (pp. 1833). Santa Cruz do Sul, RS: EDUNISC.

Witczak, M. V. C. \& Kipper, L. M. (2020, 18 e 19 abril). Isolamento social: a vida continua. Gazeta do Sul, Santa Cruz do Sul, pp. 2.

\section{Dados sobre os autores:}

- Marcus Vinicius Castro Witczak: Professor adjunto do Departamento de Ciências da Saúde e do Programa de Pós-Graduação em Psicologia da Universidade de Santa Cruz do Sul (UNISC), ministrando principalmente as disciplinas relacionadas às áreas da Psicologia Organizacional e do Trabalho e orientações de estágio e trabalho de conclusão de curso.

- Karine Vanessa Perez: Psicóloga, Doutora em Psicologia Social e Institucional (UFRGS), Estágio pós-doutoral em Educação pela Université du Québec à Montréal (UQAM), Professora do Departamento de Ciências da Saúde e do Programa de Pós-Graduação em Psicologia da Universidade de Santa Cruz do Sul (UNISC).

- Makely Ferreira Rodrigues: Psicóloga, Mestranda no Programa de Pós-Graduação em Psicologia da Universidade de Santa Cruz do Sul (UNISC), Professora do Centro de Educação Profissional da UNISC (CEPRU UNISC), Psicóloga no Setor de Desenvolvimento Humano do Hospital Santa Cruz (HSC).

\footnotetext{
Declaração de Direito Autoral

A submissão de originais para este periódico implica na transferência, pelos autores, dos direitos de publicação impressa e digital. Os direitos autorais para os artigos publicados são do autor, com direitos do periódico sobre a primeira publicação. Os autores somente poderão utilizar os mesmos resultados em outras publicações indicando claramente este periódico como o meio da publicação original. Em virtude de sermos um periódico de acesso aberto, permite-se o uso gratuito dos artigos em aplicações educacionais e científicas desde que citada a fonte conforme a licença CC-BY da Creative Commons.
} 